Article

\title{
Precise Monitoring of Soil Salinity in China's Yellow River Delta Using UAV-Borne Multispectral Imagery and a Soil Salinity Retrieval Index
}

\author{
Xinyang Yu ${ }^{1,2}$, Chunyan Chang ${ }^{1}$, Jiaxuan Song ${ }^{1}$, Yuping Zhuge ${ }^{1, * \mathbb{D}}$ and Ailing Wang ${ }^{1}$ \\ 1 College of Resources and Environment, Shandong Agricultural University, Tai'an 271018, China; \\ yuxy.12b@igsnrr.ac.cn (X.Y.); chyan0103@sdau.edu.cn (C.C.); SJxuan020903@163.com (J.S.); \\ ailingwang@sdau.edu.cn (A.W.) \\ 2 Tropical Research and Education Center/Department of Agricultural and Biological Engineering, Institute of \\ Food and Agricultural Sciences, University of Florida, Homestead, FL 33031, USA \\ * Correspondence: zhugeyp@sdau.edu.cn
}

check for updates

Citation: Yu, X.; Chang, C.; Song, J.; Zhuge, Y.; Wang, A. Precise Monitoring of Soil Salinity in China's Yellow River Delta Using UAV-Borne Multispectral Imagery and a Soil

Salinity Retrieval Index. Sensors 2022, 22, 546. https://doi.org/10.3390/ s22020546

Academic Editors: Jiyul Chang and Sigfredo Fuentes

Received: 6 November 2021

Accepted: 8 January 2022

Published: 11 January 2022

Publisher's Note: MDPI stays neutral with regard to jurisdictional claims in published maps and institutional affiliations.

Copyright: (C) 2022 by the authors. Licensee MDPI, Basel, Switzerland. This article is an open access article distributed under the terms and conditions of the Creative Commons Attribution (CC BY) license (https:// creativecommons.org/licenses/by/ $4.0 /)$.

\begin{abstract}
Monitoring salinity information of salinized soil efficiently and precisely using the unmanned aerial vehicle (UAV) is critical for the rational use and sustainable development of arable land resources. The sensitive parameter and a precise retrieval method of soil salinity, however, remain unknown. This study strived to explore the sensitive parameter and construct an optimal method for retrieving soil salinity. The UAV-borne multispectral image in China's Yellow River Delta was acquired to extract band reflectance, compute vegetation indexes and soil salinity indexes. Soil samples collected from 120 different study sites were used for laboratory salt content measurements. Grey correlation analysis and Pearson correlation coefficient methods were employed to screen sensitive band reflectance and indexes. A new soil salinity retrieval index (SSRI) was then proposed based on the screened sensitive reflectance. The Partial Least Squares Regression (PLSR), Multivariable Linear Regression (MLR), Back Propagation Neural Network (BPNN), Support Vector Machine (SVM), and Random Forest (RF) methods were employed to construct retrieval models based on the sensitive indexes. The results found that green, red, and near-infrared (NIR) bands were sensitive to soil salinity, which can be used to build SSRI. The SSRI-based RF method was the optimal method for accurately retrieving the soil salinity. Its modeling determination coefficient $\left(R^{2}\right)$ and Root Mean Square Error (RMSE) were 0.724 and 1.764, respectively; and the validation $R^{2}, R M S E$, and Residual Predictive Deviation $(R P D)$ were $0.745,1.879$, and 2.211.
\end{abstract}

Keywords: soil salinity sensitive parameter; random forest; support vector machine; optimal retrieval model; remote sensing

\section{Introduction}

Soil is a vital component of the ecosystem. It plays a crucial role in the structure and operation of the land ecosystem [1,2]. However, the degradation of soil resources has emerged as one of the world's most pressing ecological concerns. Soil salinization has already become a significant symptom of soil degradation that affects $10 \%$ of the world's agricultural land [3,4]. The search for a reliable monitoring index and precise regression method for soil salinity is essential to globally assess soil salinization and its severe implications for agriculture and food security.

Ecological parameter measurement and airborne/satellite remote sensing (RS) monitoring technologies are two commonly utilized soil salinity assessment methods. Traditional methods rely on field surveys and electrical conductivity measurements, which are accurate but time and labor-intensive [5,6], and do not allow for monitoring of the spatial distribution pattern of soil salinity content. Multi- and hyperspectral satellite RS technology has been used in soil salinity monitoring since the 1990s [7,8]. Azabdaftari et al. (2016), for 
instance, computed vegetation indexes in the Adana region of Turkey using Landsat multispectral images from four different times [9]. Morgan et al. (2018) forecasted soil salinity in Cairo, Egypt using Sentinel-2 multispectral data [10]. Hyperspectral images such as EO-1 and HJ-1A were also employed as data sources to accurately detect soil salinity [11,12]. Different from the satellite RS means, the Unmanned Aerial Vehicle (UAV)-borne spectral sensors are highly maneuverable and have been used to monitor soil salinity since the 2010s. $\mathrm{Hu}$ et al. (2019) used electromagnetic induction equipment and a hyperspectral camera mounted on a UAV platform to evaluate and estimate field-scale soil salinity [13]. Ivushkin (2019) looked into the use of UAVs to measure salt stress in quinoa plants [14]. Wang et al. (2019) extracted the salt content of extremely salty soil in China's Yellow River Estuary and compared the retrieval findings with the inverse distance weighted interpolation results to achieve more accurate saline soil extraction [15]. To boost the spectral resolution to retrieve soil salinity, Ma (2020) combined Sentinel-2A and UAV multispectral images to increase the spectral resolution to inverse regional soil salinity [16]. Satellite RS imagery-based soil salinity studies have indicated that the index in the visible to infrared spectrum may better measure soil salinity, which can increase the accuracy of soil salinity retrieval [17-19]. The majority of vegetation indexes can indirectly indicate soil salinity [20]. However, few studies focused on the detection of UAV band information sensitive to soil salinity, which is essential for the construction of a reliable soil salinity monitoring index to help efficiently predict the soil salinity conditions.

For the soil salinity regression method, several approaches such as partial least square (PLS), BP Neural Network (BPNN), Support Vector Machines (SVM), and random forest (RF) were introduced and applied [15,21]. For instance, Ma (2018) increased the accuracy of soil salinization retrieval by combining numerous mathematical changes on soil surface reflectance with regression analysis of collected soil data [12]. Machine learning algorithms were used by Yao et al. (2019) to infer agriculture soil salt concentration from UAV multispectral RS images [22]. The determination coefficients for validation were more than 0.69. To improve regional retrieval precision, Chen et al. (2021) presented a differentiated fusion method for calculating satellite and ground spectral variables of soil salinity based on sample differences [23]. Spectral parameters and correlation salinity indexes have been converted and filtered to retrieve soil salinity. In resource management and allocation, the river delta region has a high degree of social-ecological interdependence and competition. In China, the Yellow River Delta (YRD) features shallow groundwater levels (0-2 m), significant salinity, and surface salinity. Soil salinization affects over 70\% of YRD's land, making the region's biological ecosystem severely vulnerable [24]. Soil salinization has long been a major source of soil degradation in the YRD, limiting local agricultural productivity. Precise monitoring of soil salinity is essential to assess soil salinization. However, screening and design of sensitive parameters, as well as a suitable retrieval method, is, nevertheless, unknown.

This study thus strived to explore the sensitive parameter and construct an optimal method for soil salinity retrieval. The Yellow River Delta (YRD) in China was selected as the study area to experiment. UAV RS image and ground truth data collected during the spring season were used as the data source. Sensitive bands and spectral parameters of soil salinity were identified using grey correlation analysis and Pearson correlation coefficient approaches. PLSR, MLR, BPNN, SVM, and RF modeling methods were used to create soil salt retrieval models based on reflectance, vegetation index, and salinity index. The accuracies were evaluated quantitatively to find the optimal retrieval model. This study is expected to serve as a guide for the selection of sensitive criteria and the optimal soil salinity prediction algorithms, which can be used in other regions to retrieve soil salinity efficiently.

\section{Materials and Methods}

\subsection{Study Area}

The study was conducted in a representative arable region of Kenli District, YRD $\left(37^{\circ} 35^{\prime} 6^{\prime \prime} \sim 37^{\circ} 35^{\prime} 14^{\prime} \mathrm{N}, 118^{\circ} 20^{\prime} 31^{\prime \prime} \sim 118^{\circ} 20^{\prime} 46^{\prime \prime} \mathrm{E}\right)$. The climate of the study area is a tem- 
perate continental monsoon climate, which is dry and windy in spring. With a potential evapotranspiration-precipitation ratio of 7.6, potential evapotranspiration considerably outnumbers precipitation in spring, resulting in limited vegetation covering in the study area and severe salt deposition in the soil. The groundwater table is also shallow and mineralized. Arable and abandoned lands are the most common land uses, and coastal (tidal) salty soil with a light texture and high capillary action is the most common soil type. Hydrogeological conditions in the study area may contribute to soil salinization [25].

\subsection{Image Acquisition and Preprocessing}

The spring season in the study area is the period of high evapotranspiration and accumulation of soil salinity, which is crucial for the development of winter wheat. On 19 March 2021, a field survey was conducted to collect soil samples and obtain UAV images (Figure 1). The DJI Matrice 600 Pro (SZ DJI Technology Co., Ltd. Shenzhen, China) and the Parrot Sequoia agriculture multispectral camera, which includes Green (G), Red (R), Red Edge (REG), and Near-infrared (NIR) bands, are part of the UAV image acquisition system (Table 1). During the UAV image acquisition period, the UAV's flying height was set to $50 \mathrm{~m}$, and the spatial resolution was set to $5 \mathrm{~cm}$. Each flight trace had a $60 \%$ overlap ratio. After that, the UAV image and the associated GPS data were loaded into the Pix4D Mapper for preprocessing, which included geometric correction, radiometric calibration, and orthorectification.
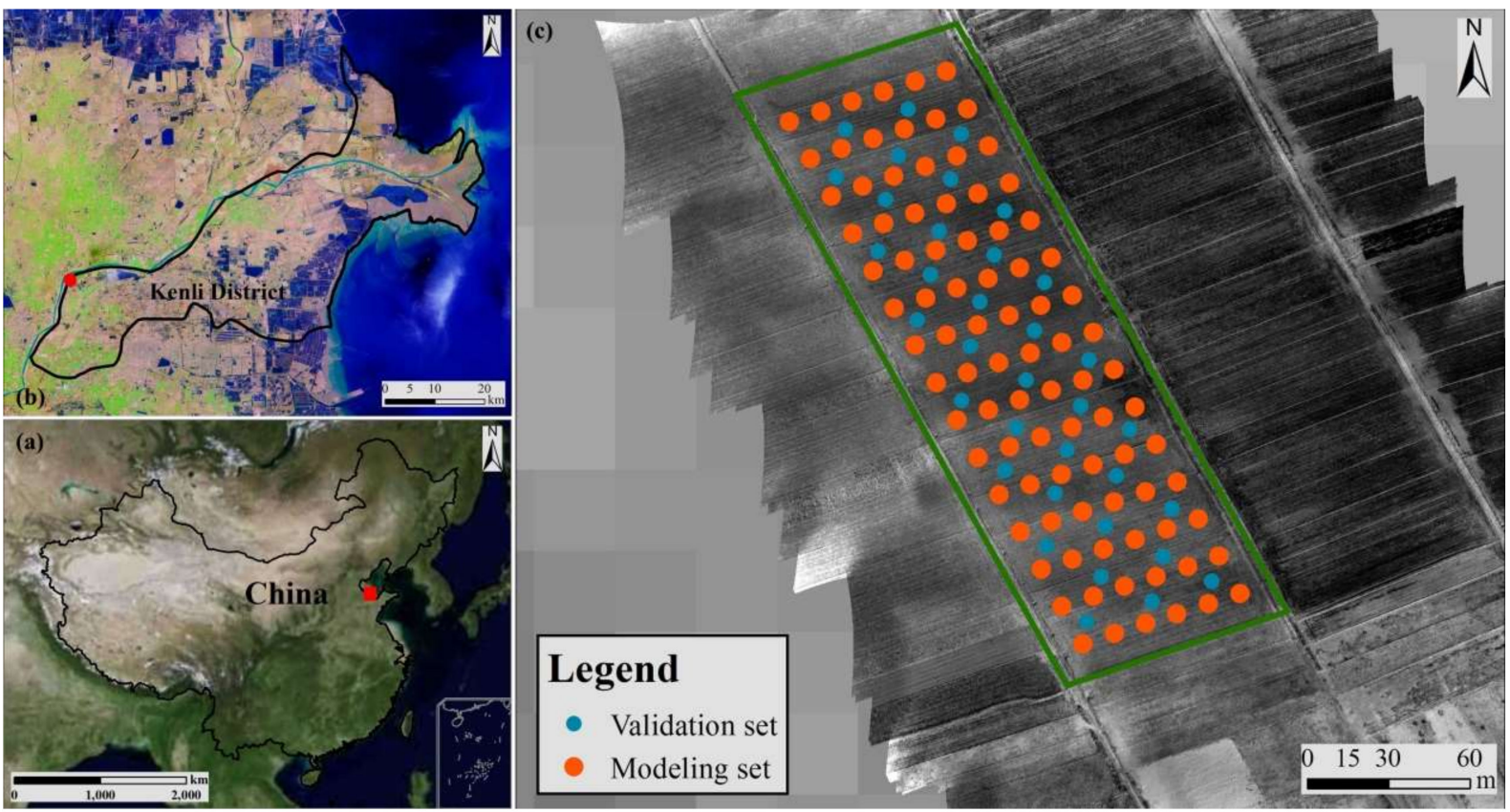

Figure 1. Location of the study area. (a) Location of the Kenli District in China; (b) test area in the Kenli district; (c) UAV image covering the test area.

Table 1. Band information of multispectral camera sensor.

\begin{tabular}{ccccc}
\hline ID & Band & Abbreviation & Center Wavelength (nm) & Bandwidth (nm) \\
\hline 1 & Green & G & 550 & 40 \\
2 & Red & R & 660 & 40 \\
3 & Red edge & REG & 735 & 10 \\
4 & Near-infrared & NIR & 790 & 40 \\
\hline
\end{tabular}

\subsection{Soil Sampling and Laboratory Procedures}

One hundred and twenty sample sites and 40 ground control points were evenly distributed in the test area. An EC110 portable salinity meter equipped with a 2225FST 
series probe (in which the temperature correction for the electrical conductivity had already been completed) (Spectrum Technologies Inc., Dallas/Fort Worth, TX, USA) was used to make five measurements at and near each sampling site, with a range of no more than $5 \mathrm{~cm} \times 5 \mathrm{~cm}$. Using the five-point sampling approach, samples from $0-10 \mathrm{~cm}$ soil surface layer were taken at each survey location and put into separate sealed plastic bags. Meanwhile, the hand-held differential GPS (Trimble GEO 7X, Trimble Inc., Sunnyvale, CA, USA) was used to record the longitude and latitude coordinates of each sampling location, while the camera captured and recorded the surrounding environmental information.

Soil samples were treated in the laboratory for natural air drying at room temperature. Coarse fragments such as stones were discarded. All the soil samples were then physically milled, thoroughly mixed, sieved to obtain the fraction less than $2 \mathrm{~mm}$ (fine earth fraction), and packaged in separate bags for salt content analysis. The soil samples were processed into the soil solution at a soil-to-water ratio of 1:5 [26,27]. The soil conductivity value was measured using an EC110 conductivity meter, and 30 extracts were chosen at random to compute the matching soil total salt concentration [28]. Equation (1) depicts the conversion connection between soil total salt concentration and extraction solution conductivity in the studied region [4].

$$
S_{t}=2.180 \times E C_{1: 5}+0.727
$$

where $S_{t}$ is the total salt content of the soil $(\mathrm{g} / \mathrm{kg})$, and $E C_{1: 5}$ is the conductivity of soil extract $(\mathrm{mS} / \mathrm{cm})$ with a soil-water ratio of 1:5. $E C_{1: 5}$ is used to calculate the total salt content of different soil samples without measuring the ion composition, as shown in Equation (1). For each treatment, the measurement was performed five times.

\subsection{Construction of Soil Salinity Retrieval Index}

The sensitive reflectance will be used to build a new soil salinity retrieval index. Before that, the correlation coefficient technique and grey correlation analysis between band reflectance and soil salinity content were primarily computed to screen sensitive band reflectance. The grey correlation analysis technique is a statistical analysis approach using several factors. It is used to calculate the degree of correlation among components based on the similarity or dissimilarity of development patterns among factors, i.e., the grey correlation degree [29]. The Pearson correlation coefficient measures the degree of linear association between two distance variables. The Pearson correlation analysis is a type of factor correlation analysis that is appropriate for continuous variables [30]. Besides, the band diagnostic index $\left(P_{i}\right)$ was employed in this study to further improve the accuracy and reliability of screening sensitive band reflectance. The calculation equation of the band diagnostic index is shown below.

$$
P_{i}=R_{i} \times \sigma_{i}
$$

where $R_{i}$ is the correlation coefficient between the reflectance value on each band and the soil salinity, and $\sigma_{i}$ is the standard deviation of reflectance value of band $i$ [31].

\subsection{Validation}

To examine the performance of the new proposed index, six vegetation indexes, six salinity indexes, and one brightness index were used as comparisons to conduct screening, model construction, and validation process. The vegetation index is calculated using the standard multispectral RS bands R and NIR, and it includes the Normalized Difference Vegetation Index (NDVI), Difference Vegetation Index (DVI), Soil Adjusted Vegetation Index (SAVI), and Ratio Vegetation Index (RVI). Based on the band operation of the NDVI, the Green Normalized Difference Vegetation Index (GNDVI) and the Red Normalized Difference Vegetation Index $\left(\mathrm{NDVI}_{\mathrm{REG}}\right)$ were calculated and classed as VI indexes. The salinity index stands for the soil salinity index. It is represented by six algebras (SI-T, SI1, SI2, SI3, NDSI, and SRSI), with Soil Remote Sensing Index (SRSI) being the transformation and synthesis index of the Soil Salinity Index SI1 and the vegetation index NDVI (Table 2). The brightness index (BI) is determined using the R and NIR bands. 
Table 2. Spectral indexes and equations. G represents the reflectance of the green band, $\mathrm{R}$ denotes the reflectance of the red band, REG is the reflectance of the red edge band, and NIR is the reflectance of the near-infrared band.

\begin{tabular}{|c|c|c|c|}
\hline Index Type & Spectral Index & Equation & Reference \\
\hline \multirow{6}{*}{ VI } & Normalized Difference Vegetation Index (NDVI) & $\frac{N I R-R}{N I R+R}$ & [19] \\
\hline & Difference Vegetation Index (DVI) & NIR $-\mathrm{R}$ & [19] \\
\hline & Soil Adjusted Vegetation Index (SAVI) & $\underline{(1+\mathrm{L}) \times(\mathrm{NIR}-\mathrm{R})}, \mathrm{L}=0.5$ & [32] \\
\hline & Ratio Vegetation Index (RVI) & $\frac{\mathrm{NIR}}{\mathrm{R}}$ & [32] \\
\hline & Green Normalized Difference Vegetation Index (GNDVI) & $\frac{N I R-G}{N I R+G}$ & [33] \\
\hline & Red Normalized Vegetation Difference Index (NDVI $\left.{ }_{\text {REG }}\right)$ & $\begin{array}{l}\text { NIR-REG } \\
\text { NIR-REG }\end{array}$ & [33] \\
\hline \multirow{6}{*}{ SI } & Salinity Index (SI-T) & $\frac{\mathrm{R}}{\mathrm{NIR}} \times 100$ & [34] \\
\hline & Salinity Index 1 (SI1) & $\sqrt{G \times R}$ & [34] \\
\hline & Salinity Index 2 (SI2) & $\sqrt{\mathrm{G}^{2}+\mathrm{R}^{2}+\mathrm{NIR}^{2}}$ & [35] \\
\hline & Salinity Index 3 (SI3) & $\sqrt{G^{2}+R^{2}}$ & [35] \\
\hline & Normalized Difference Salinity Index (NDSI) & $\frac{\mathrm{R}-\mathrm{NIR}}{\mathrm{R}+\mathrm{NIR}}$ & [36] \\
\hline & Soil Remote Sensing Index (SRSI) & $\sqrt{(\mathrm{NDVI}-1)^{2}+\mathrm{SI}^{2}}$ & {$[32]$} \\
\hline $\mathrm{BI}$ & Brightness index (BI) & $\sqrt{\mathrm{R}^{2}+\mathrm{NIR}^{2}}$ & [36] \\
\hline
\end{tabular}

The soil salinity retrieval model and comparison techniques were constructed using QGIS, SPSS, and Matlab. Based on the newly constructed index and sensitive VI and SI, the retrieval models of soil salinity were built using the Partial Least Squares Regression (PLSR [37]), Multivariable Linear Regression (MLR [38]), Back Propagation Neural Network (BPNN [39]), Support Vector Machine (SVM [40]), and Random Forest (RF [41]) methods. The determination coefficient $\left(R^{2}\right)$, root mean square error (RMSE), and residual predictive deviation $(R P D)$ were employed to evaluate the regression results. $R^{2}$ represents the consistency with which the model was established and validated. If $R^{2}$ is near to one, the model is more robust and has a better fitting degree. The RMSE is used to evaluate the model's prediction performance. The lower the RMSE, the better the model's prediction ability. The RPD is the ratio of the measured value's standard deviation to the predicted error. When RPD is less than 1.4, the model cannot predict measured values; $1.4 \leq R P D<2$ indicates that the model can roughly predict those values, and $R P D$ more than or equal to 2.0 shows that the model has exceptional prediction ability. Models with high $R^{2}$ and $R P D$ values perform better in terms of prediction and stability [42].

\section{Results}

\subsection{Statistical Analysis of Soil Samples}

The soil salt concentration varied from 0.264 to $20.651 \mathrm{~g} / \mathrm{kg}$ throughout the test area, with an average of $7.583 \mathrm{~g} / \mathrm{kg}$ and a standard deviation of $5.766 \mathrm{~g} / \mathrm{kg}$ (Table 3). The salinity of the soil in the test area was typically high. Modeling set's soil salinity varied from 0.277 to $20.675 \mathrm{~g} / \mathrm{kg}$, with an average of $7.575 \mathrm{~g} / \mathrm{kg}$ and a standard deviation of $5.735 \mathrm{~g} / \mathrm{kg}$. Validation set's soil salinity varied from 0.258 to $20.250 \mathrm{~g} / \mathrm{kg}$, with an average of $7.627 \mathrm{~g} / \mathrm{kg}$ and a standard deviation of $5.864 \mathrm{~g} / \mathrm{kg}$. The mean and standard deviation of the modeling and validation sets are comparable to the statistical findings of all sample sets, which may decrease model creation and validation deviation in the latter stage and has modeling reliability.

\subsection{Selection of Sensitive Bands}

The correlation findings of UAV image reflectance showed that grey correlation coefficients have larger absolute values than Pearson correlation coefficients for the four-band reflectance and soil salinity content. Grey correlation coefficients between G, R, NIR, and salinity content were $0.567,0.569$, and 0.612 , respectively, and were all significant at the 
0.01 level (Table 4). Relative correlation coefficients were $0.532(p<0.01), 0.522(p<0.01)$, and 0.557 ( $p<0.01$ ) for $\mathrm{G}, \mathrm{R}, \mathrm{NIR}$, and salinity content, which showed the same pattern as that of the grey correlation. Among the four bands, NIR had the greatest correlation coefficient.

Table 3. Statistics of soil salinity content.

\begin{tabular}{cccccc}
\hline Sample Set & $\begin{array}{c}\text { Minimum } \\
(\mathbf{g} / \mathbf{k g})\end{array}$ & $\begin{array}{c}\text { Maximum } \\
\mathbf{( g / k g )}\end{array}$ & $\begin{array}{c}\text { Average } \\
\mathbf{( g / k g )}\end{array}$ & $\begin{array}{c}\text { SD } \\
(\mathbf{g} / \mathbf{k g})\end{array}$ & Sample Size \\
\hline All & 0.264 & 20.651 & 7.583 & 5.766 & 120 \\
Modeling set & 0.277 & 20.675 & 7.575 & 5.735 & 90 \\
Validation set & 0.258 & 20.250 & 7.627 & 5.864 & 30 \\
\hline
\end{tabular}

Table 4. Correlation analysis of sensitive reflectance with soil salinity.

\begin{tabular}{ccc}
\hline Reflectance & Grey Correlation Coefficient & Pearson Correlation Coefficient \\
\hline G & $0.567^{* *}$ & $0.532^{* *}$ \\
R & $0.569^{* *}$ & $0.522^{* *}$ \\
REG & $0.550^{*}$ & $\mathrm{~S} 0.509^{*}$ \\
NIR & $0.612^{* *}$ & $0.557^{* *}$ \\
\hline
\end{tabular}

* Significant at 0.05 level, ${ }^{* *}$ significant at 0.01 level.

To further improve the accuracy and reliability of screening sensitive band reflectance, the diagnostic index $P_{i}$ of $\mathrm{G}, \mathrm{R}, \mathrm{REG}$, and NIR were computed. We can find that G, B, and NIR bands were higher than that of REG (Table 5), which further indicated that the soil reflectance of green, red, and near-infrared bands of UAV multispectral image were sensitive to soil salt information, which can be used to construct a sensitive soil salinity retrieval index.

Table 5. Diagnostic index of UAV image reflectance.

\begin{tabular}{ccccc}
\hline & G & R & REG & NIR \\
\hline$R_{i}$ & $0.567^{* *}$ & $0.569 * *$ & $0.550^{*}$ & $0.612^{* *}$ \\
$\sigma_{i}$ & 0.791 & 0.761 & 0.470 & 0.732 \\
$P_{i}$ & 0.472 & 0.456 & 0.273 & 0.435 \\
\hline
\end{tabular}

${ }^{*}$ Significant at 0.05 level, ${ }^{* *}$ significant at 0.01 level.

\subsection{Construction of Soil Salinity Retrieval Model}

This study compared various combinations of the three-soil salinity sensitive bands ( $R$, G, and NIR), e.g., addition, subtraction, and division (Table 6), and analyzed the relationship between these transformation indexes and soil salinity information. Finally, we devised a new index, namely the Soil Salinity Retrieval Index (SSRI, Equation (3)) to detect soil salinity by relying on the three sensitive bands.

$$
\text { SSRI }=\frac{\mathrm{NIR}}{\sqrt{\mathrm{R} * \mathrm{G}}}
$$

where $G, R$, and NIR is the green, red, and near-infrared band reflectance of the UAV image, respectively.

Table 6. Equation combinations of the G, R, NIR.

\begin{tabular}{cc}
\hline ID & Algebra Operation \\
\hline 1 & R+G+NIR \\
2 & R-G-NIR, G-R-NIR, NIR-R-G \\
3 & $\sqrt[3]{\mathrm{R} * \mathrm{G} * \mathrm{NIR}}$ \\
4 & $\frac{\mathrm{R}}{\sqrt{\mathrm{G} * \mathrm{NIR}}}, \frac{\mathrm{G}}{\sqrt{\mathrm{R} * \mathrm{NIR}}}, \frac{\mathrm{NIR}}{\sqrt{\mathrm{R} * \mathrm{G}}}$ \\
\hline
\end{tabular}




\subsection{Correlation Analysis}

The correlations of proposed SSRI, VIs, and SIs with soil salinity content were shown in Table 7. Among the 14 indexes, SSRI showed the higher grey correlation and Pearson correlation coefficients, 0.689 and 0.632 , respectively. NDVI and DVI were the only two VIs that demonstrated a significant association $(p<0.01)$, with NDVI having the strongest correlation $(0.619,0.602)$. SI, SI-T, SI3, NDSI, and SRSI had a significant association with soil salinity $(p<0.01)$, with SRSI having the highest value of correlation (Table 7$)$. Therefore, NDVI, SRSI, and SSRI were utilized to build soil salinity retrieval models.

Table 7. Correlation analysis of sensitive spectral index with soil salinity.

\begin{tabular}{ccc}
\hline Spectral Index & Grey Correlation Coefficient & Pearson Correlation Coefficient \\
\hline SSRI & $0.689^{* *}$ & $0.632^{* *}$ \\
\hline NDVI & $0.619^{* *}$ & $0.602^{* *}$ \\
DVI & $0.601^{* *}$ & $0.557^{* *}$ \\
SRVI & $0.512^{*}$ & $0.476^{*}$ \\
RVI & $0.517^{*}$ & $0.458^{*}$ \\
GNDVI & $0.557^{* *}$ & $0.514^{*}$ \\
NDVI REG & $0.507^{*}$ & $0.454^{*}$ \\
\hline Salinity Index (SI-T) & $0.607^{* *}$ & $0.559^{* *}$ \\
Salinity Index 1 (SI1) & $0.556^{* *}$ & $0.514^{*}$ \\
Salinity Index 2 (SI2) & -0.390 & -0.200 \\
Salinity Index 3 (SI3) & $0.637^{* *}$ & $0.601^{* *}$ \\
NDSI & $0.535^{*}$ & $0.474^{*}$ \\
SRSI & $0.677^{* *}$ & $0.615^{* *}$ \\
\hline Brightness Index (BI) & $0.235^{*}$ & 0.229 \\
\hline Significant at 0.05 level $* *$ significant at 0.01 level. &
\end{tabular}

\subsection{Retrieval Accuracy}

The RF, BPNN, SVM, PLSR, and MLR were used to create retrieval models of soil salinity based on the NDVI image. The results showed that the NDVI-based RF model showed the highest modeling and validation accuracies $\left(R^{2}=0.625\right.$ and 0.633$)$ among the five methods and then was BPNN, SVM, PLSR, and MLR in order of modeling and validation accuracies (Table 8). However, only the RPD of the RF model topped 1.4, which is the rough sample prediction threshold. Therefore, in the test area, NDVI is not suited for accurate soil salinity retrieval.

Table 8. Accuracy statistics of the NDVI based retrieval model.

\begin{tabular}{cccccc}
\hline \multirow{2}{*}{ Modeling Method } & \multicolumn{2}{c}{ Modeling Accuracy } & \multicolumn{3}{c}{ Validation Accuracy } \\
\cline { 2 - 6 } & $\boldsymbol{R}^{\mathbf{2}}$ & $\boldsymbol{R M S E}$ & $\boldsymbol{R}^{\mathbf{2}}$ & $\boldsymbol{R M S E}$ & $\boldsymbol{R P D}$ \\
\hline RF & 0.625 & 2.977 & 0.633 & 2.789 & 1.425 \\
BPNN & 0.601 & 3.375 & 0.610 & 3.090 & 1.397 \\
SVM & 0.584 & 3.547 & 0.591 & 3.274 & 1.363 \\
PLSR & 0.557 & 3.645 & 0.566 & 3.455 & 1.321 \\
MLR & 0.492 & 3.988 & 0.488 & 4.714 & 0.670 \\
\hline
\end{tabular}

Table 9 displayed the statistically accurate findings of the five modeling approaches using SRSI. According to the statistical data, the accuracy of modeling and validation of the five modeling approaches is in the following order: RF > BPNN > PLSR > SVM > MLR. Except for the MLR model, the modeling and validation accuracy of the other four models are all more than 0.6 . The vegetation index has the potential to extract soil salinity with acceptable accuracies.

In the test area, the $R^{2}$ values of RF, BPNN, SVM, PLSR, and MLR based on SSRI (Table 10) showed stronger fitting impacts than the retrieval model based on NDVI and 
SRSI (Tables 8 and 9). Furthermore, the modeling and validation accuracies of the five techniques (RF, BPNN, SVM, PLSR, and MLR) were all higher than 0.6, and the RPD of the RF model is more than 2.2 (Table 10), which indicates that the RF has adequate soil salinity retrieval capacity.

Table 9. Accuracy statistical results of SRSI retrieval model.

\begin{tabular}{cccccc}
\hline \multirow{2}{*}{ Modeling Method } & \multicolumn{2}{c}{ Modeling Accuracy } & \multicolumn{3}{c}{ Validation Accuracy } \\
\cline { 2 - 6 } & $\boldsymbol{R}^{\mathbf{2}}$ & $\boldsymbol{R} \boldsymbol{M S E}$ & $\boldsymbol{R}^{\mathbf{2}}$ & $\boldsymbol{R M S E}$ & $\boldsymbol{R P D}$ \\
\hline RF & 0.667 & 2.554 & 0.679 & 2.443 & 1.878 \\
BPNN & 0.641 & 2.631 & 0.653 & 2.781 & 1.750 \\
SVM & 0.619 & 3.205 & 0.621 & 3.029 & 1.549 \\
PLSR & 0.633 & 2.980 & 0.639 & 2.991 & 1.583 \\
MLR & 0.537 & 3.652 & 0.526 & 3.631 & 0.998 \\
\hline
\end{tabular}

Table 10. Accuracy statistical results of soil salinity index retrieval model based on SSRI.

\begin{tabular}{cccccc}
\hline \multirow{2}{*}{ Modeling Method } & \multicolumn{2}{c}{ Modeling Accuracy } & \multicolumn{3}{c}{ Validation Accuracy } \\
\cline { 2 - 6 } & $\boldsymbol{R}^{\mathbf{2}}$ & $\boldsymbol{R M S E}$ & $\boldsymbol{R}^{\mathbf{2}}$ & $\boldsymbol{R M S E}$ & $\boldsymbol{R P D}$ \\
\hline RF & 0.724 & 1.764 & 0.745 & 1.879 & 2.211 \\
BPNN & 0.699 & 1.989 & 0.682 & 2.376 & 2.043 \\
SVM & 0.665 & 2.554 & 0.658 & 3.002 & 1.675 \\
PLSR & 0.671 & 2.275 & 0.689 & 2.897 & 1.748 \\
MLR & 0.639 & 3.091 & 0.622 & 2.994 & 1.464 \\
\hline
\end{tabular}

The comparison of the modeling and validation accuracies (Tables 8-10) indicated that the retrieval models based on the proposed SSRI were more accurate than those based on vegetation index and soil salinity index. The soil salt retrieval modeling and validation accuracy were all greater than 0.638 , and the $R P D$ values were all greater than 1.463 . Besides, among the five prediction modeling approaches, the order of modeling and validation accuracy was RF, BPNN, PLSR, SVM, and MLR. The modeling and validation accuracies of the RF modeling approach in various models were all greater than 0.6 , and $R P D$ values were above 1.424 (Tables 8-10). Among them, the $R^{2}$ and $R M S E$ of the modeling set using the SSRI-based RF method were 0.724 and 1.746; and the $R^{2}, R M S E$, and $R P D$ of the validation set were $0.745,1.879$, and 2.211 (Figure 2), which were the highest. The optimal retrieval model of soil salinity in the test area is the SSRI-based RF method.

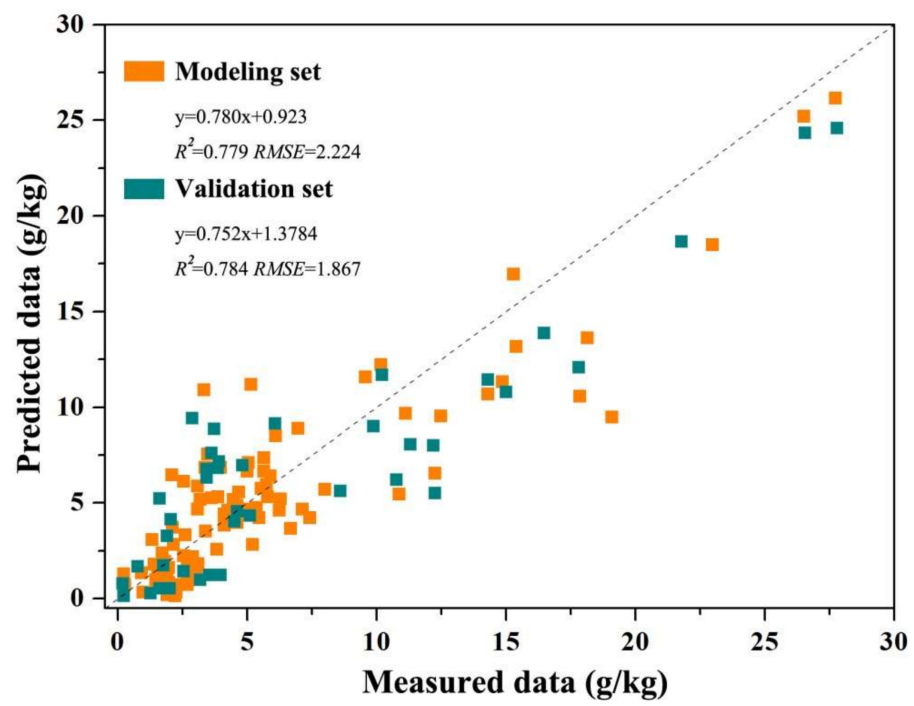

Figure 2. Scatter plot of the optimal retrieval model (SSRI-based RF method) of soil salinity based on UAV imagery. 


\section{Discussions}

The sensitive parameter and optimal retrieval method for soil salinity monitoring using UAV multispectral imagery were investigated in this study. The proposed soil salinity retrieval index (SSRI) based RF method was found to show the best accuracy in predicting soil salinity. The modeling $R^{2}$ and RMSE were 0.724 and 1.764 , respectively; and the validation $R^{2}$, RMSE, and $R P D$ were $0.745,1.879$, and 2.211 , respectively, which were the highest among all the models built using the five prediction approaches based on SSRI, vegetation index, and salinity index.

Compared to existing soil salinity retrieval studies using UAV imagery, this study screened sensitive band information and combined them to form a feasible index to help retrieve soil salinity. The retrieval values of soil salinity in the whole test area using the SSRI-based RF model (Figure 3) ranged from 0.323 to $21.210 \mathrm{~g} / \mathrm{kg}$, with an average value of $6.871 \mathrm{~g} / \mathrm{kg}$, which was close to the descriptive statistical results of the soil samples (Table 3). The test area can be divided into five grades based on the saline soil grading standard (Wang et al., 2019), namely extremely saline soil (salt content greater than $10.0 \mathrm{~g} / \mathrm{kg}$ ), severely saline soil (salt content $6.0-10.0 \mathrm{~g} / \mathrm{kg}$ ), moderately saline soil (salt content 4.0-6.0 g/ kg), slightly saline soil (salt content $2.0-4.0 \mathrm{~g} / \mathrm{kg}$ ), and non-saline soil (Figure 3). According to the area statistical figures, the extremely saline soil occupied the lowest share of 5.3 percent of the five grades. Severely and moderately saline soil zones accounted for 15.5 and 13.6 percent of the overall test area, respectively. The proposal of slightly saline soil was 65.4 percent, the highest of the five categories. This pattern of soil salinity distribution is consistent with the observation in Figure 2, i.e., more than half of the sample locations were in the slightly saline region. The non-saline region encompassed 10.2 percent of the left test area. The geographical analysis demonstrated that soil salinization is widespread in the test area, with the majority of test sites belonging to the saline soil grade.

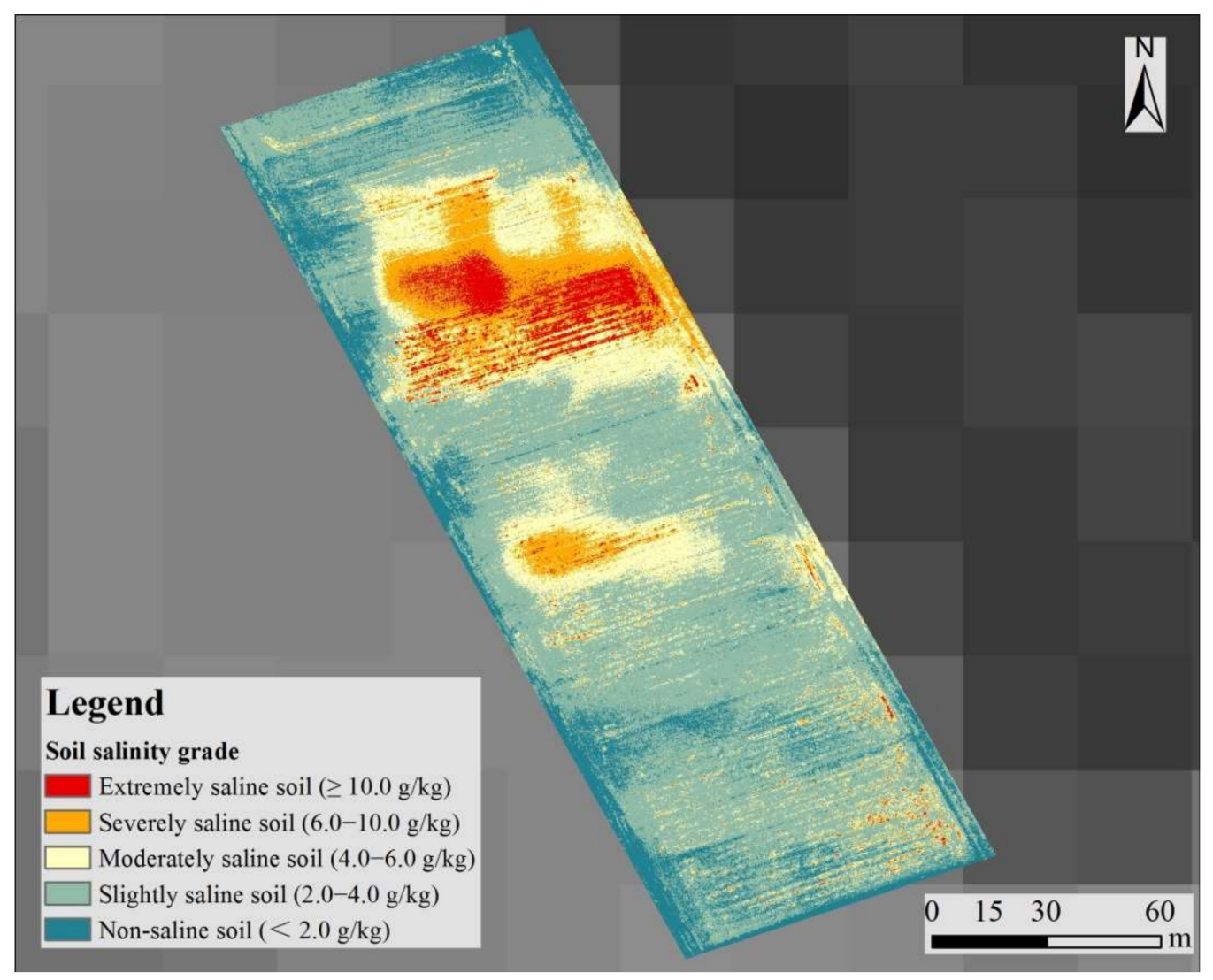

Figure 3. Retrieval map of soil salinity using the SRSI based RF method. 
Visible and NIR bands displayed significant correlation links with soil salinity according to the results of two spectral screening analysis methodologies. The main minerals involved in the salinization of the soil of the YRD are rock salt and gypsum, with the main anions being $\mathrm{Cl}^{-}$and $\mathrm{SO}_{4}{ }^{2-}$ and the main cations being $\mathrm{Na}^{+}$and $\mathrm{Ca}^{2+}[11,43]$. Previous research found that although $\mathrm{NaCl}$ has no spectral characteristics in the visible and near-infrared bands, $\mathrm{NaCl}$ is correlated with gypsum [44]. Gypsum possesses absorption qualities in the visible and near-infrared bands, which can help reveal soil salinity spectral information. Xu et al. (2018) found that gypsum has molecular vibration absorption spectrum features in the NIR band, visible and NIR band can collect $\mathrm{SO}_{4}{ }^{2-}$ spectral information [45]. Furthermore, studies have shown that salinized soil has higher reflectance in the visible and NIR bands than non-salinized soil $[15,46]$. Hence, spectral information of salinized soil retrieved from RS data can be used to estimate soil salinity in visible and near-infrared bands.

This study explored the sensitive parameters and optimal method to retrieve soil salinity, while soil samples were collected in the surface layer of soil $(0-10 \mathrm{~cm})$. For agriculture and food security, more attention should be paid to the indirect approach to a salinization assessment of root-zone $(0-100 \mathrm{~cm})$ [47]. Besides, the soil sample collection and measurement were conducted in one site. The proposed SSRI and the findings need more examination to test the reliability in further research. Furthermore, UAV multispectral image and the SSRI-based RF method can efficiently predict soil salinity with acceptable accuracy, whereas the UAV's battery duration time prevents it from being used in large regional-scale soil salinity assessment. Recently, studies have fused satellite RS data with UAV images to derive regional-scale soil salinity, which is useful for estimating soil salinity across wide areas. However, it should be noted the variations in band wavelengths, meteorological conditions at the time of acquisition, and sensor compatibility between aviation and aerospace platforms are distinctly different. How to eliminate these uncertainties is a direction where further endeavors should be made in.

\section{Conclusions}

This study explored the sensitive parameter and optimal method for the accurate retrieval and spatial distribution of soil salinity. The sensitive band of soil salinity was discovered to be the band G, R, and NIR, a soil salinity retrieval index (SSRI) was proposed accordingly to retrieve soil salinity. SSRI-based RF method was the optimal combination that can accurately retrieve the soil salinity. Further study will be conducted in other salinized regions to examine the findings of this study.

Author Contributions: Conceptualization, Y.Z.; methodology, C.C.; software, J.S.; validation, X.Y.; investigation, A.W.; writing-original draft, X.Y.; writing—review and editing, Y.Z. and A.W. All authors have read and agreed to the published version of the manuscript.

Funding: This research was funded by the Major Science and Technology Projects in Shandong Province, grant number 2019JZZY010723, and Natural Foundation of Shandong Province, grant number ZR2019MD014. The funders have no role in study design, data collection, and analysis, decision to publish, or preparation of the manuscript.

Institutional Review Board Statement: Not applicable.

Informed Consent Statement: Not applicable.

Data Availability Statement: Data used in this study are available under request.

Acknowledgments: We would like to thank the kind help of the editor and the reviewers to improve the manuscript.

Conflicts of Interest: The authors declare no conflict of interest. 


\section{References}

1. Green, S.M.; Dungait, J.; Tu, C.; Buss, H.L.; Sanderson, N.; Hawkes, S.J.; Xing, K.; Yue, F.; Hussey, V.L.; Peng, J.; et al. Soil functions and ecosystem services research in the Chinese karst critical zone. Chem. Geol. 2019, 527, 119107. [CrossRef]

2. Norris, C.E.; Quideau, S.A.; Landhusser, S.M.; Drozdowski, B.; Hogg, K.E.; Oh, S.W. Assessing structural and functional indicators of soil nitrogen availability in reclaimed forest ecosystems using 15 n-labeled aspen litter. Can. J. Soil Sci. 2018, 98, 357-368. [CrossRef]

3. Ghassemi, F.; Jakeman, A.J.; Nix, H.A. Salinisation of Land and Water Resources: Human Causes, Extent, Management and Case Studies; CAB international: Canberra, Australia, 1995; pp. 1-3.

4. Wang, Z. Spatial and Temporal Variability of Soil Moisture and Salinity, Affecting Factors and Forecasting Model in the Typical Area of the Yellow River Delta. 2017. Available online: https:/ /d.wanfangdata.com.cn/thesis/D01212536 (accessed on 8 February 2018).

5. Fourati, H.T.; Bouaziz, M.; Benzina, M.; Bouaziz, S. Detection of terrain indices related to soil salinity and mapping salt-affected soils using remote sensing and geostatistical techniques. Environ. Monit. Assess 2017, 189, 177. [CrossRef] [PubMed]

6. Koganti, T.; Narjary, B.; Zare, E.; Pathan, A.L.; Huang, J.; Triantafilis, J. Quantitative mapping of soil salinity using the dualem-21s instrument and em inversion software. Land Degrad. Dev. 2018, 29, 1768-1781. [CrossRef]

7. Jiang, H.; Shu, H. Optical remote-sensing data based research on detecting soil salinity at different depth in an arid-area oasis, Xinjiang, China. Earth Sci. Inform. 2018, 12, 43-56. [CrossRef]

8. Wang, D. Quantitative Inversion of Water and Salt in Coastal Saline Soil in the Yellow River Delta; Shandong Agricultural University: Tai'an, China, 2020.

9. Azabdaftari, A.; Sunar, F. Soil salinity mapping using multitemporal Landsat data. ISPRS-Int. Arch. Photogramm. Remote Sens. Spat. Inf. Sci. 2016, 7, 3-9. [CrossRef]

10. Morgan, R.S.; Abd, E.-H.M.; Rahim, S. Soil salinity mapping utilizing sentinel-2 and neural networks. Indian J. Agric. Res. 2018, 52, 524-529. [CrossRef]

11. Weng, Y.L.; Gong, P. Soil salinity measurements on the Yellow River Delta. J. Nanjing Univ. Nat. Sci. 2006, 42, 602-610.

12. Ma, C. Retrieval of soil salt content based on Sentinel-1 dual-polarization radar image. Trans. Chin. Soc. Agric. Eng. 2018, 34, 153-158.

13. Hu, J.; Peng, J.; Zhou, Y.; Xu, D.; Shi, Z. Quantitative estimation of soil salinity using uav-borne hyperspectral and satellite multispectral images. Remote Sens. 2019, 11, 736. [CrossRef]

14. Ivushkin, K.; Bartholomeus, H.; Bregt, A.K.; Pulatov, A.; Franceschini, M.H.; Kramer, H.; van Loo, E.N.; Roman, V.J.; Finkers, R. Uav based soil salinity assessment of cropland. Geoderma 2018, 338, 502-512. [CrossRef]

15. Wang, D.; Chen, H.; Wang, G.; Cong, J.; Wang, X.; Wei, X. Salinity Inversion of Severe Saline Soil in the Yellow River Estuary Based on UAV Multi-Spectra. Chin. Agric. Sci. 2019, 52, 1698-1709.

16. Ma, Y.; Chen, H.Y.; Zhao, G.X.; Wang, Z.R.; Wang, D.Y. Spectral index fusion for salinized soil salinity inversion using Sentinel-2A and UAV images in a coastal area. IEEE Access. 2020, 8, 159595-159608. [CrossRef]

17. Aldabaa, A.; Weindorf, D.C.; Chakraborty, S.; Sharma, A.; Li, B. Combination of proximal and remote sensing methods for rapid soil salinity quantification. Geoderma 2015, 239-240, 34-46. [CrossRef]

18. Rao, B.; Sharma, R.; Ravi, S.; Das, S.N.; Dwivedi, R.S.; Thammappa, S.S.; Venkataratnam, L. Spectral behaviour of salt-affected soils. Int. J. Remote Sens. 1995, 16, 2125-2136. [CrossRef]

19. Shrestha, R.P. Relating soil electrical conductivity to remote sensing and other soil properties for assessing soil salinity in northeast Thailand. Land Degrad. Dev. 2006, 17, 677-689. [CrossRef]

20. Ramos, T.; Castanheira, N.; Oliveira, A.; Paz, A.; Gonalves, M. Soil salinity assessment using vegetation indices derived from Sentinel-2 multispectral data. application to Lezíria Grande, Portugal. Agric. Water Manag. 2020, 241, 106387. [CrossRef]

21. Masoud, A. Predicting salt abundance in slightly saline soils from Landsat ETM+ imagery using spectral mixture analysis and soil spectrometry. Geoderma 2014, 217-218, 45-56. [CrossRef]

22. Yao, Z.; Chen, J.; Zhang, Z.; Tan, C.; Wei, G.; Wang, X. Effect of plastic film mulching on the accuracy of soil salinity retrieval by UAV multispectral remote sensing. Trans. Chin. Soc. Agric. Eng. 2019, 35, 89-97.

23. Chen, H.; Ma, Y.; Zhu, A.; Wang, Z.; Zhao, G.; Wei, Y. Soil salinity inversion based on differentiated fusion of satellite image and ground spectra. Int. J. Appl. Earth Obs. Geoinf. 2021, 101, 102360. [CrossRef]

24. Jiang, C.; Pan, S.; Chen, S. Recent morphological changes of the Yellow River submerged delta: Causes and environmental implications. Geomorphology 2017, 293, 93-107. [CrossRef]

25. Fan, X.; Pedroli, B.; Liu, G.; Liu, Q.; Liu, H.; Shu, L. Soil salinity development in the yellow river delta in relation to groundwater dynamics. Land Degrad. Dev. 2011, 23, 175-189. [CrossRef]

26. He, Y.; Desutter, T.; Prunty, L.; Hopkins, D.; Jia, X.; Wysocki, D.A. Evaluation of 1:5 soil to water extract electrical conductivity methods. Geoderma 2012, 185-186, 12-17. [CrossRef]

27. FAO. Standard Operating Procedure for Saturated Soil Paste Extract; Global Soil Laboratory Network (GLOSOLAN): Rome, Italy, 2021.

28. Lu, R. Soil Agrochemical Analysis Method; China Agricultural Science and Technology Press: Beijing, China, 2002.

29. Yeh, Y.L.; Chen, T.C. Application of grey correlation analysis for evaluating the artificial lake site in Pingtung plain, Taiwan. Can. J. Civ. Eng. 2011, 31, 56-64. [CrossRef]

30. Li, Y. Research on Soil Salinity in the Yellow River Delta Based on Remote Sensing; Chang'an University: Xi'an, China, 2018. 
31. Piao, S.; Fang, J.; Ji, W.; Guo, Q.; Ke, J.; Tao, S. Variation in a satellite-based vegetation index in relation to climate in china. J. Veg. Sci. 2004, 15, 219-226. [CrossRef]

32. Alhammadi, M.S.; Glenn, E.P. Detecting date palm trees health and vegetation greenness change on the eastern coast of the United Arab Emirates using SAVI. Int. J. Remote Sens. 2008, 29, 1745-1765. [CrossRef]

33. Abderrazak, B.; Ali, E.B.; Rachid, B.; Hassan, R. Sentinel-MSI vnir and swir bands sensitivity analysis for soil salinity discrimination in an arid landscape. Remote Sens. 2018, 10, 855.

34. Allbed, A.; Kumar, L.; Aldakheel, Y. Assessing soil salinity using soil salinity and vegetation indices derived from ikonos high-spatial resolution imageries: Applications in a date palm dominated region. Geoderma 2014, 230-231, 1-8. [CrossRef]

35. Yahiaoui, I.; Douaoui, A.; Zhang, Q.; Ziane, A. Soil salinity prediction in the lower cheliff plain (algeria) based on remote sensing and topographic feature analysis. J. Arid. Land 2015, 7, 794-805. [CrossRef]

36. Khan, N.M.; Rastoskuev, V.V. Mapping salt-affected soils using remote sensing indicators-A simple approach with the use of GIS IDRISI. Ratio 2001, 11, 5-9.

37. Geladi, P.; Kowalski, B. Partial Least-Squares Regression: A Tutorial. Analytica Chimica Acta 1986, 185, 1-17. [CrossRef]

38. Zelterman, D. Multivariable Linear Regression; Springer International Publishing: Berlin, Germany, 2015.

39. Hecht-Nielsen, R. Theory of the Backpropagation Neural Network. Neural Netw. 1988, 1, 593-605. [CrossRef]

40. Amari, S.; Wu, S. Improving support vector machine classifiers by modifying kernel functions. Neural Netw. 1999, 12, 783-789. [CrossRef]

41. Breiman, L. Random forest. Mach. Learn. 2001, 45, 5-32. [CrossRef]

42. Terhoeven-Urselmans, T.; Schmidt, H.; Joergensen, R.G.; Ludwig, B. Usefulness of near-infrared spectroscopy to determine biological and chemical soil properties: Importance of sample pre-treatment. Soil Biol. Biochem. 2008, 40, 1178-1188. [CrossRef]

43. An, L.S.; Zhao, Q.S.; Ye, S.Y.; Liu, G.Q.; Ding, X.G. Water-salt interactions factors and vegetation effects in the groundwater ecosystem in Yellow River Delta. Adv. Water Sci. 2011, 22, 689-695.

44. Goldshleger, N.; Ben-Dor, E.; Lugassi, R.; Eshel, G. Soil degradation monitoring by remote sensing: Examples with three degradation processes. Soil Sci. Soc. Am. J. 2010, 74, 1433-1445. [CrossRef]

45. Xu, W. Spectral Discriminant Analysis of Martian Simulated Minerals and Brines; Shandong University: Weihai, China, 2018.

46. Fan, X.; Liu, Y.; Tao, J.; Weng, Y. Soil salinity retrieval from advanced multi-spectral sensor with partial least square regression. Remote Sens. 2015, 7, 488-511. [CrossRef]

47. Scudiero, E.; Skaggs, T.; Anderson, R.; Corwin, D. Soil degradation in farmlands of California's San Joaquin Valley resulting from drought-induced land-use changes. In Proceedings of the EGU General Assembly Conference Abstracts, Vienna, Austria, 23-28 April 2016; EPSC2016-728. 